\title{
Induction motor rotor bars type effects towards energy efficiency, economic and environment
}

\author{
Yanawati Yahya, Mohd Khairil Rahmat \\ Renewable Energy Research Laboratory (RENERAL), Electrical Engineering Section, British Malaysian Institute, \\ Universiti Kuala Lumpur, Malaysia
}

\begin{tabular}{|c|c|}
\hline Article Info & ABSTRACT \\
\hline Article history: & Nowadays, the rotating motor is the most demoralized machine for the global \\
\hline Received Oct 11 2019 & Motor industry. Comfort of practice, start-up, small, weightiness, Increased \\
\hline Revised Dec 22, 2019 & efficiency, low maintenance and inexpensive for each power rating that \\
\hline Accepted Jan 11, 2020 & ierally meets the necessary features for industries. Efficient improvements \\
\hline Accepted Jan 11, 2020 & $\begin{array}{l}\text { are inspected with copper for the rotor bars slot. Usually, the copper loss in } \\
\text { the induction motor Rotor division contributes to the loss of energy. The }\end{array}$ \\
\hline Keywords: & slot, size and design. These tasks were inspected using two approaches, in \\
\hline Bar design & particular, MotorSolve (IM) and calculations in theory. One set of simulation \\
\hline Bar size & $\begin{array}{l}\text { has shown a significant increase in energy efficiency for a new rotor frame } \\
\text { design. Calculations in theory are used MATLAB As a result these new }\end{array}$ \\
\hline Cost saving & designs have improved energy efficiency by $77 \%$ as compared to its $74 \%$ \\
\hline Emission reduction & existing design. The results proved to be using MATLAB. For energy, cost \\
\hline Energy efficiency & savings and emission reduction (ER), new design rotor frame has been saved \\
\hline Energy saving & 154KWH/year, utility bill $\mathrm{RM} 60.20 /$ Year and $0.113 \mathrm{CO} 2$ tons/years \\
\hline Induction motor & intended for individually motor. Finally, the estimated cost aimed at 100,000 \\
\hline Rotor bar type & $\begin{array}{l}\text { pieces of new rotor bars pattern induction motor and indicates this price was } \\
\text { kept almost RM6 million. }\end{array}$ \\
\hline
\end{tabular}

This is an open access article under the CC BY-SA license.

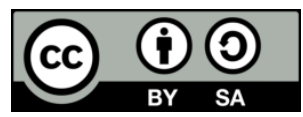

\section{Corresponding Author:}

Yanawati Yahya,

Renewable Energy Research Laboratory (RENERAL),

Electrical Engineering Section, British Malaysian Institute,

Universiti Kuala Lumpur, 53100 Gombak, Selangor Malaysia.

Email: yanawatiyahya@yahoo.com

\section{INTRODUCTION}

Three Phase Induction Motor evaluation is influenced by some features equipped with various types of rotor bars that reduce energy efficiency. The induction Motor is the installation with various types of rotor bars can disturb current and voltage use due to reduce power loss and energy efficient factors. The rotating motor identified by means of the "asynchronous motor", the greatest commonly used electric motor in the manufacturing division. In general, the rotating machine is low-priced and easy to sustain as equated to other electric machines. The rotating machine is completed of static part (stator) and rotating part (rotor). Winding stator involves of a sequence of low resistance that are forever focused on motor frame. The rotating (rotor) comprises into 2 types, namely wound and squirrel cage rotor. The rotating and stastic part is disconnected thru air space (others name is air gaps) that consent rotor free rotate [1]. A cage rotor involves of a core cylinder lamination that has a parallel slot on the outer diameter. Beside that, the copper or aluminium bars is located in every bars slot. A squirrel-cage rotor consists of an exposed brass bar, a slightly longer than the rotor that has been strapped into the slot. The different ends merge with two copper brass ring all shortcut 
bars consisting. Entire structure bar and final ring resemble the cage of the squirrel [2]. Induction motor loss involves of loss of resistance in rotor cage, iron loss, friction \& windage losses, and other losses. Copper and aluminium aimed at each leg round at $20^{\circ} \mathrm{C}$ are $10.37 \Omega$ and $16.06 \Omega$ distinctly. By the side of this step, the similar current needs, in converting copper with aluminium is a decrease in the loss of resistance. These Impression led to deliver a copper bars in the non-aluminium rotor bars structure. Thus, increased machine efficient due to the detail that copper power conductivity is approximately $60 \%$ higher compared to aluminium [3]. Induction motor rotor method is another method for increasing rotating machine efficiency. Towards developing the evaluation of the rotating machine rotor bars can be separated into some parts of the rotor bars, the number of rotor bars and diameter bars. Aiming to distype the same rotor bars, if small iron loss volume with reduced lamination thickness will lead to increase rotating machine efficient. According to simulated results, it shows that the entire types of bar has more efficient with $1.2 \%$ relative to external rotation and internal bars that $77 \%$ and $76 \%$ respectively [4]. As a result, for the whole type bars is suitable towards the efficient improvement of rotating machine. Then, the figure of flat-rounded rotor is affected by the induction motor efficient. Early researchers have been stated that when increasing the number of rounded bars can increase energy efficient and decrese power loss comparing to reduce the quantity of rounds bars in the rotor part [5].

Moreover, the rotor bars slot dimension will increase the efficiency afterward referring to the earlier researcher. After increasing the rotor bar slots dimension, it will decrease the losses of power in the rotating machine due to the increase in the rotor bar conductivity. This means that when losing power reduce in induction motor efficiency becomes more effective [6]. In a concept intended to design and analysis for rotating machine and generators, the MotorSolve IM software consumes a limited component of the decision to verify the pattern design and analysis are precise. It consumes a decoration that is based on users with a simple holder of various editable rotor and stator parts. There is a number of aspects that can be a justification into a motor description that is a loss of iron, inductances leakage, efficiency, deep bar effects, sloping, final effect and effect of changing motor features due to the fed phase inverter [7]. Subsequently assessing the rotating machine pattern via Motorsolves IM simulate process it will continue to verify the pattern with method hypothetically math solves via MATLAB. The determination of responsibility this technique is to verify the induction motor cage that has respectable evaluation in terms of efficiency and proving the first simulated results process. Then, the method of mathematic in theory has in progress via the MATLAB programming equivalence technique. Calculations such as impedance of stator, rotor \& air gap, efficiency and power loss have been specified. Determination of this mathematic is to verify the results MATLAB. According to the mathematical calculations, which will benefit in design and verify the rotating motor via MATLAB simulation [8]. This data is then investigated the breakdown of machinery energy consumption, peak and off-peak procedure comportment, power factor and energy consumption of certain trends. The energy inspection results were presented that the uppermost electrical energy-using machinery was an electric motor, pumps and air compressors. This research study mentions that around $64 \%$ electrical energy was used in peak hours thru the industry and the average power factor reached from 0.88 to 0.92 . This research was assessed the energy and bill savings consuming high efficiency electric motor sideways with the profit period [9]. Today, the electricity is an important to evolution and development. In contrast, in the process of electricity generation by fuel, a number of toxic by-products affect the conservation of natural ecosystems. Furthermore, the use of electrical equipment due to gas fueled anti-environment also effects on human health and climate. This study focuses on the estimated energy consumption, energy saving, reduction of greenhouse gas emissions for the use of home utilizations in Malaysia between 1999 and 2015. The outcomes from this research study shows that a large amount of energy can be saved and that a large amount of toxic emissions can be controlled [10].

Emissions in the use of the process of producing adverse effects on the environment that affect human health, the growth of organisms and climate change. Energy savings as much as possible to cut the generation of electricity from power plants. Consequently, the $\mathrm{CO}_{2}$ reduction and additional productions from the oils used by the energy partition can budget [11]. The cooling tower is single of the significant in industrial services and housing facilities. These research paper evaluations the energy efficient, economic and conservational profits of cooling tower. The energy-saving procedures with the use of high-efficient motor and variable speed drive were used to save more energy. At $50 \%$ load condition, using high-efficient motor, reduction of emissions is about 6.97 ton of $\mathrm{CO}_{2}, 38,400 \mathrm{~kg}$ of $\mathrm{SO}_{2}, 18,109 \mathrm{~kg}$ of NOx and 4,601 $\mathrm{kg}$ of $\mathrm{CO}$. the number of utility bills can be saved by using high-efficiency motor and apply VSDs. Can be concluded that using the variable speed drive and high-efficient motor, the economic and emissions can be saved [12]. The process of three phase rotating machine is founded upon the application of Faraday's Law and the Lorentz Force on a rod. The one set of electromagnets in an AC induction motor is designed in the stator due to the AC supply related to the stator windings. The alternating nature of voltage supply induces an electromagnetic force (EMF) in the rotor as Lenz's law principle, which is generating another set of 
electromagnets; its call as induction motor. Like most motors so an AC induction motor has a fixed outer portion and called as the stator, and a rotor that rotate inside of motor with a carefully and between of them have air gap. Virtually, the all electrical motors are using the magnetic field rotation to rotate the rotor [13]. Charles I. Hubert in his book "Electric Machines: Theory, Operation, Applications, Adjustment and control" found that the three-phase squirrel cage rotating machine was created by Nikola Tesla in 1888 [14]. It involves no electric contacts to the rotating part and the transmission energy from the stationary part to the rotating part is by means of electromagnetic induction. A rotating magnetic field is produced by a stationary winding, induced an alternating emf and current in the rotor part. The rotating flux or known as rotating field is produced by three phase current in stator winding coils that will be linked to the rotating field that produced by a magnet sweeping around the rotor. The rotating field that cuts the rotor bars in term counter clockwise (CCW) sweep around the rotor bars. According to Lenz's law that the voltage, current, and flux are generated by the relative motion between a conductor (rotor bars material), and magnetic field and have direction to oppose the relative motion. Hence, to verify the Lenz's law so the conductors must develop a mechanical force and have same direction as indicated by the rotating flux $(\mathrm{CCW})$. It is because the generated flux due to rotor bar current must be clockwise $(\mathrm{CW})$. The direction of rotor bar current that produces by CW flux is determined by the right-hand rule [14]. TEC Electric Motors in their Motor Catalogue 2013 mention that the motors are categorized through roughness and efficienct. They are factorymade via state of the apparatus to exacting standards in order to certify presentation and consistency. A broad diversity is accessible to suit agricultural and industrial tenders such as compressors, power looms, sugar cane crushers, rice mills, and Industrial apparatus [15]. VTU e-Learning Centre extended their analysis and revealed that a proper numbers of rotor bars slots are designated in relation to the stator slots number or else disagreeable effects will be found at the starting of the motor. The cogging and crawling are the two spectacles that experimental due to unsuitable combination of number of rotor bars slots and stator slots. Thus, this study aims to investigate the best implement and selection of number between stator slots and rotor bars slots to get the best rotor induction motor in terms of high efficiency with minimum the losses [16]. Several studies have attempted to describe about National Electrical Manufacturers Association (NEMA) design for classification and performance characteristics. Bezesky \& Kreitzer found that the performace characteristic for all design such as Design A shows have low slip and high efficiencies, Design B has high efficiencies, low slip, variable torque, constant torque and horsepower applications, Design $\mathrm{C}$ to assist the high starting torque requirements, higher losses and lower efficiency compared to design B and Design D are used in high starting torque or high inertia loads [17]. Compared to Charles I. Hubert argue that the Design A has higher breakdown torque with higher starting current, Design B serves as the basis for comparison of motor performance with other design, Design $\mathrm{C}$ has higher locked rotor torque, lower breakdown torque with higher starting torque, Design D has higher locked rotor torque and high slip and Design E was high efficiency, lower locked rotor torque [18]. Presently, Ali Emadi extended their analysis about Design A has high torque, low slip with high locked amperes, Design B has normal torque and slip with normal locked amperes, Design $\mathrm{C}$ has high torque, normal slip with normal locked amperes and Design D has high locked rotor torque with high slip [19].

The ecosphere aspects acute energy crises produced by the need for renewable energy sources. The increase in demand and conservational issues controlled to an increase in renewable energy. Solar energy is increasing and used by many countries but output power is not constant due to two radiation and temperature factors. MPPT algorithm is used to increase overall efficiency. Perturb and detecting the most commonly used MPPT techniques due to simplicity [20]. This paper provides an overview of the three phase 5level packed U cell (PUC5) inverter fed Feeding Motor Induction from renewable energy sources for electric vehicles and water pumps specified in agricultural sectors. Inverter PUC5 requires a minimum number of semiconductor devices, the PV panel and only one capacitor in each phase. The results show good dynamic performance in different conditions [21]. Induction motors are systems that operate at their speeds, but there are applications that require speed operation. There is control of the speed method of induction motor techniques. A powerful tool used to control the induction motor and the controller system performance will be improved. Mathematical models of controllers, encoded in MATLAB. Modeling and control will be shown by less than one state of resistance [22]. This paper proposes a Direct Torque Control (DTC) fivephase motor drive with reduced torque. The method presented here is based on the DTC DTC backstepping classical works by continuously switching frequency inverter. This method significantly increases the torque of torque and flux and improve the dynamics of the drive by making it less sensitive to disturbance load torque. The proposed method was developed and designed using Matlab / SIMULINK to demonstrate the effectiveness and performance of DTC-Backstepping [23].

Many theories and studies have been proposed to explain the bars material for three phase squirrel cage induction motor rotor. Kenneth G. Budinski \& Michael K. Budinski argued that the copper materials are widely used for bus bars, wiring terminals, and the conductor bar similarity. There is pure copper with even 
higher conductivity if the application warrants the extra cost. In summary, the copper and copper alloys are indispensable engineering materials [24]. Similarly, the early theories of Cowie, Brender, \& Peters focused on aluminium has been the universal conductor material at the squirrel cage induction motor and mostly because ease to manufacture by pressure die casting. Short lifetime of die casting with a higher melting copper will cause high production cost and prevented the copper rotor from attaining a place in integral horsepower motors. Because of its higher electrical conductivity compared to aluminium. The copper in the rotor bars can be reduces energy losses [25]. Copper Development Association Inc. \& International Copper Association in their investigation was mentions that the substitute copper with aluminium in the "squirrel cage" structure of induction motor rotor is a way to improve the electrical energy efficiency of induction motor. The copper rotor appeared to be the best approach and much more cost effective than introducing amorphous iron laminations or superconducting windings. The motor modelling by a number of manufacturers had shown that induction motors rotor bars with copper-containing rotors would yield overall loss reductions from $15 \%$ to $20 \%$ compared to the aluminium. It is because the copper has the highest electrical conductivity compared to the aluminium which are $5.96 \times 10^{7}$ siemens $/$ meter and $3.77 \times$ $10^{7}$ siemens/meter at $20^{\circ} \mathrm{C}$ [26]. Moreover, through the use of higher conductivity copper with better steel shows that the efficiency of induction motor can be improved. To maintain satisfactory performance by way starting torque, current and motor design techniques have been developed and also shaping of rotor bars to present appropriate frequency dependent of impedance. Economical manufacture of cast copper motor rotors is made possible by advances in casting technology [27]. This study and research aims are investigating the NEMA design three-phase induction motor rotor for round bars type with high efficiency, lower losses, and save energy. Induction Motor investigation and analysis by altering the type of bars, materials, designs and sizes for the purpose of enhancing induction Motor efficiency. The technique used is the computational theory resolved via a simulated MATLAB. Simulated software is castoff in this study namely MotorSolve (IM) and MATLAB simulation. The resolution of simulation and computational theory is to compare the results among two approaches in terms of increased rotating machine competencies have been presented.

\section{MOTORSOLVE (IM) SOFTWARE SIMULATION: ROTOR PART CHARACTERISTIC'S}

This section presents the works and methods that had been done in the research project. Performance analysis on the $0.5 \mathrm{Hp} 3$-phase induction motor with different rotor bars design have been done using which are MotorSolve IM software and MATLAB. The simulate and comparison are started using finite element method (FEM) software which is MotorSolve IM and MATLAB. The parameters that are fixed value which are general, stator and coil winding setting. The variable value is the rotor setting while the responding variable is the result of induction motor. The variable parameters in rotor setting such as thickness, bar material, core material, bar type, bar diameter and end rings. This simulation is done until the good performance of induction motor in term of the efficiency, power factor, torque and losses obtained. In addition, a calculation for the equivalent circuit is calculated and compared. All the analytical calculation of stator, rotor \& air gap impedance, efficiency, power factor, torque and losses were specified. The determination of this analytical math is to validate the simulation result. Figure 1 demonstrations the requiring of the rotor typical for 3-phase rotating motor via MotorSolve (IM) software. The bars type and core dimension were changed based on design and analysis. The representative different in the rotating part as designate in Figure 1.

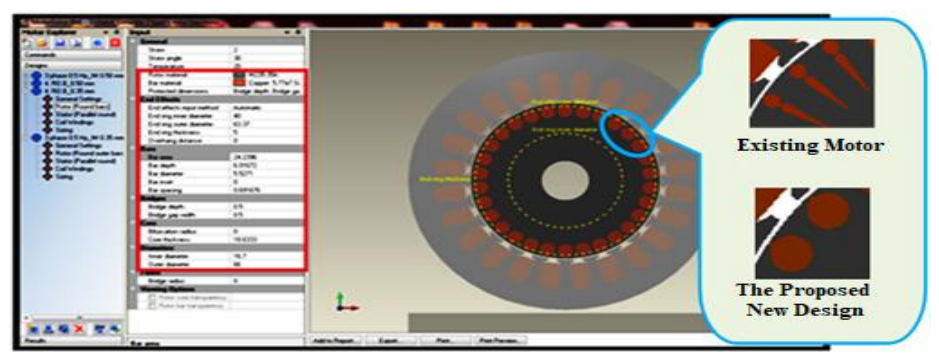

Figure 1. Requiring the rotating part via motorsolve (IM)

Other than that, the bar bridge angle, bar spacing, bridge depth, bridge gap width, bifurcation thickness, core thickness, inner diameter and outer diameter are also must be change accordingly as shown in Table 1. Table 1 shows the value of parameters in specifying the rotor typical for 3-phase induction motor. 
Table 1. The value of parameters in specifying the rotor part typical for 3-phase induction motor

\begin{tabular}{llll}
\hline Parameters & Values & Parameters & Values \\
\hline Bridges depth & $4.786 \mathrm{~mm}$ & Bridge gap width & $0.5 \mathrm{~mm}$ \\
Inner Diameter & $16.7 \mathrm{~mm}$ & Outer diameter & $66.0 \mathrm{~mm}$ \\
Rotor Material & M235 & Rotor Thickness Model 1 & $0.35 \mathrm{~mm}$ \\
Bar Material & Copper & Rotor Thickness Model 2 & $0.50 \mathrm{~mm}$ \\
\hline
\end{tabular}

\section{RESULTS AND DISCUSSION}

This section presents the outcome of performance evaluation of $0.5 \mathrm{Hp}$, three-phase induction motor with different rotor bars type. The performance result of three phase induction motor has been done by using MotorSolve (IM) software and MATLAB which include simulation and theoretical calculation. The induction motor with round rotor bar and parallel round stator was chosen for this design. According to Daut I. et al., the usage of this slot pattern for rotor bars due to it has a discrete 'starting bar' isolated from the main body of the conductor bar by a 'leakage slot', is related to motors with high conductivity material in the rotor cage [5]. In addition, this rotor bar design has a higher locked rotor torque and a high slip .

\subsection{The assessment outcomes for two patterns thru motorsolve (IM)}

The rotating bars type pattern is evaluated via evaluation graph in terms of efficiency development for both rotor bars slot patterns via the MotorSolve (IM). The efficiency chart line versus speed for two rotor bars slot patterns was shown in Figure 2.

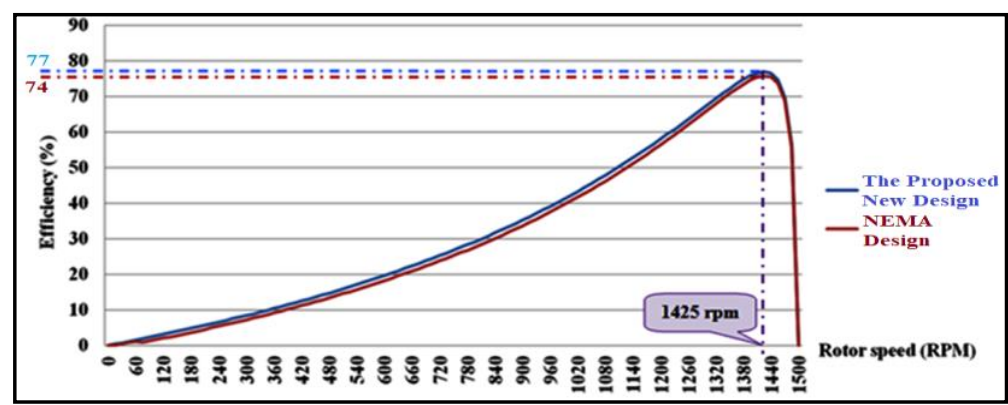

Figure 2. The graph line of efficiency versus speed for both rotor bars slot design

By reffering to Figure 2, it displays the chart line of efficiency versus speed for both rotor bars slot pattern such as current and new design. According to Figure 2, the chart line displays the energy efficiency for the proposed new pattern is increase to $77 \%$ as likened to the current pattern of $74 \%$. The proposed new pattern has an efficiency increase of $4 \%$ liken to the current pattern. It is due to the efficient of energy is reverse proportionate to the losses. Decreasing the total loss, the efficient of energy will be rise.

\subsection{The assessment verify outcome among motorsolve (IM) \& MATLAB for the new pattern}

Tern (1) displays the connection among core loss and efficiency of rotating machine. The efficiency of the rotating machine can be founded via (1) as below:

$$
\text { Efficiency, } \eta=\frac{P_{\text {OUT }}}{P_{I N}} \times(100 \%)=\left(\frac{P_{I N}+P_{\text {CORE LOSS }}}{H_{p} \times 746}\right) \times 100 \%
$$

Where $\eta$ is efficiency, $\mathrm{P}_{\text {OUT }}$ is output power, $\mathrm{P}_{\mathrm{IN}}$ is input power, $\mathrm{P}_{\text {CORE LOSS }}$ is core loss power and $\mathrm{Hp}$ is horsepower $(0.5 \mathrm{Hp})$. The efficiency value will be affected from the increase or any core loss based on (1). New pattern proposals are analysed with a set simulate result and MATLAB that are prescribed in terms of energy efficiency. Chart efficiency towards the speed of both simulations has been shown in Figure 3 . 


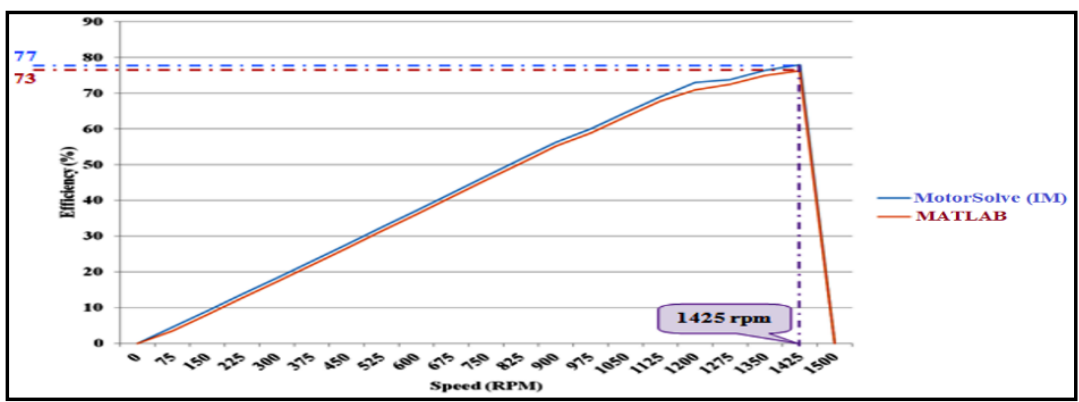

Figure 3. Curve chart of efficiency versus speed for two software

Figure 3 shows the curve of efficiency (\%) versus speed (rpm) for both both software. According to Figure 3, when speed reaches at $1425 \mathrm{rpm}$ shows the value of induction motor efficiency for MotorSolve (IM) is $77 \%$. The result of energy efficiency was verified with MATLAB simulation is $73 \%$. According to the curve graph outcome is the proposed new pattern has increased the energy efficiency and will produce range value from $76 \%$ to $78 \%$. It is because, based on (1), the efficiency is inverse proportional to the losses (core loss). When reducing the value of total loss, the efficiency value will increase.

\section{ANALYSIS}

The flux distribution patterned zone for the rotor frame is on the rotor core. The rate of flux distribution for the new pattern is accurate $0.97 \mathrm{~T}$ although the current pattern is accurate $1.22 \mathrm{~T}$. Intended for a good pattern design, core density flux value can exceed more than $1 \mathrm{~T}$. It is due to the density of flux more than $1 \mathrm{~T}$, flux going through a ventilation hole that is axis of the core rotor. In the meantime, a reduction in areas for the flux movement must be considered. It confirms the new pattern is a good pattern design compared to the current pattern.

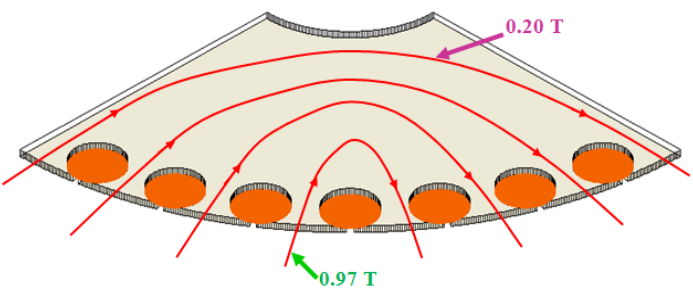

(a)

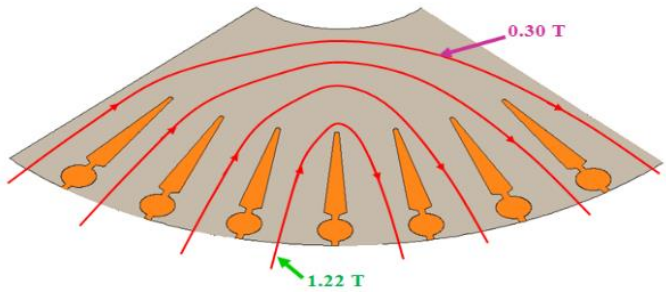

(b)

Figure 4. Distribution flux for two rotor bars pattern, (a). New Rotor Bars Pattern, (b). Existing Rotor Bars Pattern

Figure 4 displays a distribution flux for two rotor bars pattern. By reffering to the Figure 4 , the flux distribution value nearby the shaft area is lower than flux density in the Bar's rotor area of $0.2 \mathrm{~T}$ from the interior and 0.97 exterior for the new pattern. The value of the current flux pattern is $0.3 \mathrm{~T}$ of Interior and $1.22 \mathrm{~T}$ on the outside. Due to if the refusal and the lengths are increasing, the magnet flux value and a flux distribution will be reduced. A magnetic circuit refusal is connected to the length, cross-catchment area and substance permeability. Figure 5 expressions the rotor bars type pattern used in designing the three-phase rotating machine. Based on Figure 5, its confirmations that the rotor core flux distribution maximum value is consuming as (2) as below:

Rotor Core Material Flux Density, $B_{r c m}=\frac{C_{1}}{\left(C_{2}-2 d_{r 1}\right) C_{3}}$

Where; $C_{1}=\Phi_{m} \quad C_{2}=D_{r}-D_{s h} \quad C_{3}=l_{b} . S F$ 
$B_{r c m}$ will not exceed 100 kilolines/in ${ }^{2}(1 \mathrm{~T})$. Unvolatile ventilation axes through the rotor core. The reduction of areas for the flux movement will be measured. It confirms that increasing the dimension bar depth $\left(\mathrm{d}_{\mathrm{r} 1}\right)$ of rotor bar type will rise the rotor core flux distribution of 3-phase rotating machine.

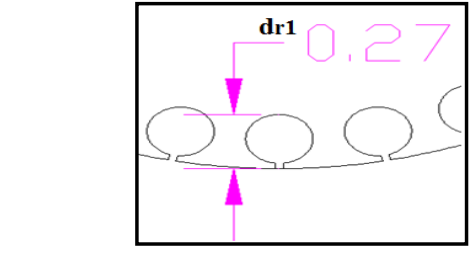

(a)

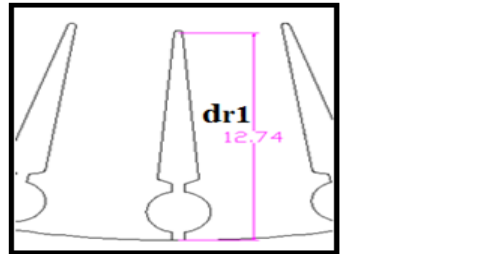

(b)

Figure 5. The rotor bars type for two patterns, (a). New Rotor Bars Type Pattern, (b). Existing Rotor Bars Type Pattern

\section{NEW ROTOR BARS PATTERN: ENERGY \& COST SAVING AND EMISSION REDUCTION}

The amount of money kept depending on the size of motor, annual hour, rise energy efficiency and quota utilities cares. The new bars design has increased nearly $4 \%$. Its confirmations the type of new design rotor bars have improved rise energy efficiency and reduced the copper loss. In Malaysia, the usefulness bill from Tenaga Nasional Berhad (TNB), the normal factory tariff is $38.0 \mathrm{sen} / \mathrm{kWh}$. The lowermost monthly care is RM7.20 for the overall monthly consumption more than $200 \mathrm{kWh} /$ month. Annual energy savings (AES) thru swapping a new rotor bars pattern was presented as (3) below.

$$
A E S=h p \times L \times 0.746 \times\left[\frac{100}{E_{S T D}}-\frac{100}{E_{C R}}\right]=0.5 \times 1 \times 0.746 k W \times\left[\frac{100}{74}-\frac{100}{76.92}\right]=19.1 \mathrm{~W}
$$

Where; AES is the annual energy savings, $h p$ is horsepower, $L$ is load factor, $h r$ is the yearly operating hours, $E_{\text {std }}$ is the current rotor efficient $(\%)$ and $\mathrm{E}_{\mathrm{ee}}$ is the new pattern design rotor efficient $(\%)$. The annual bill savings $\left(\mathrm{kWh}_{\text {savings }}\right.$ was achieved thru multiply with operating hours with stated load as (4) as below.

$$
k W h_{\text {savings }}=A E S \times h r=8064 h \times 0.0191=154 \boldsymbol{k W h}
$$

Where; $k W h_{\text {savings }}$ is the expected annual bill savings (RM), AES is the annual energy savings and $h r$ is $24 \times 336$ working days. Total cost savings (TCS) through (5) as below.

$$
T C S=(A E S \times 12 \times \text { Monthly Demand Charge })+\left(k W h_{\text {savings }} \times \text { Energy Charge }\right)=\mathbf{R M} \mathbf{6 0 . 2 0}
$$

To provide low voltage industrial tariff is reffered to tariff $\mathrm{D}$, a monthly demand charge is RM7.20 and energy charge is RM0.380 / kWh. The amount of emission that can be decrease associated with the above energy saving can be predictable via the (6) as below:

$$
E R=A E S \times E F=154 \mathrm{kWh} \times 0.73159 \mathrm{kgCO} 2 / \mathrm{kWH}=\mathbf{1 1 2 . 6 7} \mathbf{k g C O 2}
$$

Where; ER is the Emission Reduction (kg), AES is Annual Energy Saving (kWh) and EF is the Emission Factor $(\mathrm{kg} / \mathrm{kWh}) \sim$ for Malaysia is $0.73159 \mathrm{kgCO} 2 / \mathrm{kWh}$.

\section{CONCLUSION}

The study aims to prove the quantity of energy savings consuming with increasing energy efficient motors. This new pattern is replaced as a sample in assessment. In addition, the possible benefits and challenges in carrying new patterns for the industry tender were discussed. This work has confirmed that a large number of energies can be kept if increase efficient motor is replaced for industrial motors. The new rotor bars type design was considered in this research with $4 \%$ increase the efficiency than the current pattern, which would decrease the motor loss quantity. A set of simulated outcomes for new pattern proposals have been proved with MATLAB. Its that indicates the math calculation of MATLAB proves that simulated 
results from MotorSolve (IM) have been modified because the error value is below $6 \%$. Intended at saving energy and costs, the new rotor bars type design has been saved $154 \mathrm{KWH} /$ year and RM 60.20/year utility bill per motor. Last but not least, an estimated price of 100,000 new rotor bars type designs was considered and presented that the value was kept approximately RM6 million.

\section{ACKNOWLEDGEMENTS}

The authors would like to thank the Principal Researcher of Universiti Kuala Lumpur's Renewable Energy Research Laboratory (RENERAL), for the technical and financial support.

\section{REFERENCES}

[1] I. J. R. Bednarczyk, "Induction Motor Theory”, 176, 2012.

[2] D. S. B. I. Al-Oraini, "Chapter Four Three Phase Induction Machine 4.1”, 2010.

[3] S. Manoharan, N. Devarajan, S. M. Deivasahayam, G. Ranganathan, "Review on Efficiency Improvement in Squirrel Cage Induction Motor by Using Dcr Technology", Journal of Electrical Engineering, Vol 60, No 4, pp. 227-236, 2009.

[4] Y. Yanawati, and D. Maizana, "Performance Comparison on $0.35 \mathrm{~mm}$ and $0.50 \mathrm{~mm}$ thicknesses of Non-oriented Steel Sheets Using FEM", The 4th International Malaysia-Ireland Joint Symposium on Engineering, Science, and Business 2014, IMiEJS2014, Penang Island, Malaysia, 25th - 26th June 2014.

[5] I. Daut, K. Anayet, N. Gomesh, M. Irwan, M. Asri, and M. A. Rashid, "Development of 0.5 HP induction motor with reduced slots in rotor and stator core and its performance evaluation", International journal of physical sciences, Vol. 7, no. 11, 2012.

[6] Y. Yanawati, I. Daut, S. N. Shafiqin, I. Pungut, M. N. Syatirah, N. Gomesh, and N. Haidar, "Efficiency Increment on $0.35 \mathrm{~mm}$ and $0.50 \mathrm{~mm}$ Thicknesses of Non-oriented Steel Sheets for 0.5 Hp Induction Motor", International Journal of Materials Engineering, Vol 2, no. 2, pp. 1-5. 2012.

[7] MotorSolve (IM) Software, "Designing \& Modelling Induction Motor Thru MotorSolve IM", Retrieved from http://www.infolytica.com/en/products/motorsolve/im/, 2014.

[8] J. Jimmie Cathey, "Electric Machines, Analysis and Design Applying Matlab", McGraw-Hill Publishing Com. Lmt, pg 375-415, 2001.

[9] R. Saidur, N. A. Rahim, M. Hasanuzzaman, "A review on compressed air energy use and energy savings", Renewable and Sustainable Energy Reviews, Vol. 14, no. 4, pp. 1135-1153, 2010.

[10] R. Saidur, H.H. Masjuki, M.Y. Jamaluddin, S. Ahmed, "Energy and associated greenhouse gas emissions from household appliances in Malaysia", Energy Policy, Vol. 35, No. 3, pp. 1648-1657, 2007.

[11] T.M. Mahlia, " Emissions from electricity generation in Malaysia", Renewable Energy, Vol. 27, No. 2, October 2002, Pages 293-300, https://doi.org/10.1016/S0960-1481(01)00177-X, 2002a.

[12] R. Saidur, E.A. Abdelaziz, M. Hasanuzzaman, M.A.H. Mamun, "A Study of Energy Efficiency, Economic and Environmental Benefits of a Cooling Tower", International Journal of Mechanical and Materials Engineering (IJMME), Vol. 5, No. 1, pp. 87-94, 2010.

[13] J. Yu, Z. Ting, and J. Qian, "Electrical Motor Products". Woodhead Publishing Limited, ISBN: 978-0-85709-0775 (print) ISBN: 978-0-85709-381-3 (online), 2011.

[14] I. Charles Hubert, "Principles of Three Phase Induction Machines". In Stephen Helba (Ed.), ELECTRIC MACHINES: Theory, Operation, Applications, Adjustment and Control (Second Edi, pp. 133 - 136). Prentice Hall, 2002e.

[15] TEC Electric Motors, Motor Catalogue 2013, (1), 2013.

[16] VTU e-Learning Centre, "Design of Rotor: Number of Slots". Retrieved January 23, 2016, from http://elearning.vtu.ac.in/16/ENotes/Elec Mac Des/Unit6VH.pdf.

[17] D. M. Bezesky, and S. Kreitzer, "NEMA Application Guide for AC Adjustable Speed Drive Systems". In IEEE/PCIC 2001 Conference (pp. 1-10).

[18] I. Charles Hubert, "Classification, Performance, Applications and Operation of Three Phase Induction Machines". In Stephen Helba (Ed.), ELECTRIC MACHINES: Theory, Operation, Applications, Adjustment and Control (Second Edi, pp. 167 - 177). Prentice Hall, 2002a.

[19] A. Emadi, "Induction Motor Characteristics. In Energy Efficient Electric Motors", (Third Edit, pp. 1 - 17). Marcel Dekker, Inc. Retrieved from http://www.dekker.com, 2005.

[20] R. K. Bhukya, and P. S. Kumar, "Simplified down sampling factor based modified SVPWM technique for cascaded inverter fed induction motor drive”, International Journal of Advances in Applied Sciences, Vol 9, No 1, pp20-26 March 2020.

[21] V. V. Nagaraju Goriparthi, and G. Sambasiva Rao, "Three phase PUC5 inverter fed induction motor for renewable energy applications", International Journal of Power Electronics and Drive Systems (IJPEDS), Vol 11, No 1, pp 1-9, 2020.

[22] A. I. Ismael, L. E. Jumaa, and N. Khamas, "Design of $\mathrm{H}_{-} \infty$ for induction motor", International Journal of Power Electronics and Drive Systems (IJPEDS), Vol 11, No 1, pp 24-33, 2020.

[23] H. Echeikh, R. Trabelsi, H. Kesraoui, A. Iqbal, and M. F. Mimouni, "Torque ripples improvement of direct torque controlled five-phase induction motor drive using backstepping control", International Journal of Power Electronics and Drive Systems (IJPEDS), Vol 11, No 1: March 2020, DOI: http://doi.org/10.11591/ijpeds.v11.i1. 
[24] G. Kenneth Budinski, and K. Michael Budinski, "Chapter 14: Copper and Its Alloys \& Chapter 15: Aluminum and Its Alloys”. In Stephen Helba (Ed.), Engineering Materials Properties and Selection (Sixth Edit). Prentice Hall International, Inc, pp. $521-568,1999$.

[25] J. G. Cowie, D. T. Brender, and D. T. Peters, "Die-cast copper rotors for improved motor performance", (pp. 4249), 2003.

[26] Inc. Copper Development Association, and L. International Copper Association, "Technology Transfer Report The Die-Cast Copper Motor Rotor", 2004.

[27] J. L. K. Jr, J. G. Cowie, S. Member, E. F. Brush, D. T. Peters, and R. Kimmich, "Improving Induction Motor Efficiency with Die-cast Copper Rotor Cages", (pp. 1-6), 2007.

\section{BIOGRAPHIES OF AUTHORS}
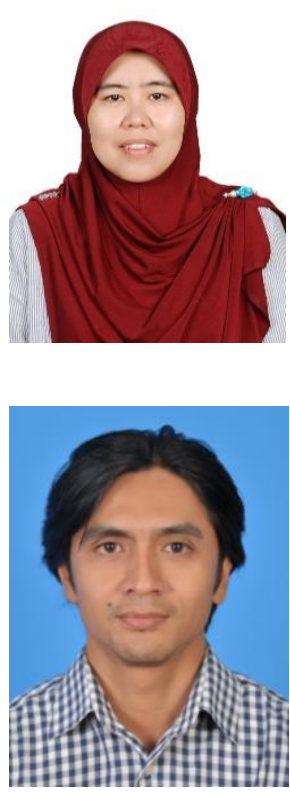

Yanawati Binti Yahya has been a Post-Doctoral Researcher at the Department of Electrical Engineering in University Kuala Lumpur (UniKL) British Malaysian Institute in Malaysia since January 2019. She received her Ph.D in Electrical Engineering System in University of Malaysia Perlis (UniMap) Malaysia. she received her MSc in Electrical Engineering System and B.Eng. (Hons) in Industrial Electronic Engineering from University Malaysia Perlis in Malaysia. She received her Diploma in Industrial Electronics Technology at University Technology Malaysia (UTM). Her research interest is in Electrical Machine Design, energy policy, energy security and modelling using FEM.

Ir. Dr. Mohd. Khairil is the Principal Researcher of Universiti Kuala Lumpur's Renewable Energy Research Laboratory (RENERAL) He has obtained his PhD. and MSc. in Electrical Power Engineering from University of Strathclyde, UK and BEng degree from University of Southampton, UK. He also has obtained MBA (Marketing) from Universiti Putra Malaysia. His research interest includes reliability study of electrical power systems, renewable energy and energy efficiency management. He has published many articles and research findings in journals and has presented in many international conferences. Prior to joining the higher education industry, he has involved in various design, installation, testing and commissioning of electrical systems mainly in the integrated electrical back-up power supply systems. He has worked with engineers and technical personnel at various levels in the United Kingdom, Australia, New Zealand, the Philippines, Singapore and Malaysia. He is a Professional Engineer with the Board of Engineers Malaysia (BEM), and a Chartered Engineer (CEng) with the Institution of Engineering and Technology (IET), UK. 